\title{
Empirical Analysis of the Psychological Hypothesis on Exchange Rate Determination and Testing Its Forecastability: The Korean Experience
}

\author{
Hyun-Jae Rhee \\ Chongju University
}

\begin{abstract}
The role of psychological impact is examined by investigating the determination of exchange rates, especially the U.S. Dollar. It has been applied to the Korean economic crisis which occurred between January 1997 and June 1999. The basic idea is that psychological information can be used in generating rational expectation, and accordingly, it would induce exchange market clearance. While psychological hypothesis is weakly supported, results reveal that the U.S. Dollar can be determined by psychological impact. The ex-post simulation process also proves it. The understanding of psychological impact is necessary for the implementation of foreign exchange policies.
\end{abstract}

- JEL Classifications: C32, F41

- Key Words: Market Sentiment, Psychological Hypothesis, GARCH-M Model

\section{Introduction}

As the world economy continuously moves toward on open system, the exchange rate plays an important role along with fundamental economic variables such as income, price, unemployment and trade balance in describing and analyzing the macroeconomic system. A number of economists has thoroughly investigated foreign exchange rates. In the original research, the exchange rate was determined by using the real sector which is based upon the trade balance, and

*Corresponding address: Assistant Professor, Hyun-Jae Rhee, Division of Economics and International Commerce, College of Economics and Business Administration, Chongju, 360-764, Korea, Tel \& Fax: +043-229-8184, E-mail: grjg7@ chongju.ac.kr.

(C2002-Center for International Economics, Sejong Institution, All Rights Reserved. 
concluded that the terms of trade are a key factor in determining exchange rates. This was because the real sector was more heavily weighted than the financial sector in this era. It reflected that the real sector which is connected to trade balance dominated international trade flow. Accordingly, purchasing power parity has long been adopted for exchange rate determination. Since purchasing power parity is calculated by the differences in general price level which comes from the real sector, usually non-tradable goods, it seems to be in line with the traditional approach.

As the share of the financial sector is gradually more weighted, the exchange rate is influenced by the interest rate parity, and it is developed to the portfolio balance approach. Foreign currency becomes a part of the assets, and it is allocated with other assets. In this case, fundamental macroeconomic variables such as money stock, interest rates, and real income influence the determination of exchange rates. Therefore, the investor is trying to maximize the return by optimally allocating investor's assets. Depending upon this approach, the analysis and forecasting of the exchange rates could not be possible without understanding the fundamental macroeconomic variables. All the previous works in this literature, however, mainly deal with long-run analysis. While the overshooting model induced an expected change in the exchange rate determination, it attempted to evaluate short-run and long-run path, simultaneously. However, the overshooting model does not provide sufficient ways to evaluate short-run analysis in exchange rate determination.

Many economists tried to find a formula to overcome it by using non-economic factors. This is completely understandable due to the fact that the exchange market is so sensitive and easily affected by non-economic fundamental variables. The economic news model is chosen as an alternative. But, such an attempt has not fulfilled the forecasting of the exchange rate determination in the short-run either. In light of this, market sentiment is emphasized in this literature. As most economists acknowledged, Asian foreign exchange markets, including Korea, suffered from a severe disequilibrium a few years ago. Such a situation provided an excellent opportunity for the evaluation of the market sentiment because the psychological impact was dramatically apparent in the foreign exchange markets of Asian countries during this period. The research covers materials from January 1997 to June 1999 and reflects the economic crisis which happened in the second half of 1997. This paper consists of the following sections. Section II is a review of literature concerning economic analysis and psychology. Section III provides a 
theoretical background, and Section IV discusses empirical results. The conclusion and its policy implication are in Section V.

\section{Literature Reviews}

Many economists have researched the psychological impact on economic behavior, and some of them have been quite successful in developing stylized fact of models by using a number of theoretical works. They are based on in consumer's behavior, decision making and investment decision. Lewin (1996), Rabin (1998), Earl (1990), Hogarth and Reder (1986) reviewed the relationship between economics and psychology. Lewin (1996) insisted that psychologists and institutionalist economists attacked the unscientific nature of economics due to the lack of psychological influences in economic analysis. Rabin (1998) concluded that psychology systematically explores human judgment, behavior, and wellbeing, and it can teach us an important lesson about how humans differ from the way they are traditionally described by economists. Standard economics assumes that each person maximizes stable and coherent preferences given rationally formed probabilistic beliefs, but psychological research teaches us ways to describe preferences more realistically about biases in belief formation and about ways it is misleading to conceptualize people as attempting to maximize stable, coherent, and accurately perceived preferences. Earl (1990) reviewed recent literature that integrates economics and psychology, contrasting economists' views of rationality with psychologists' research on how expectations and actions are affected by problems of cognition. The discussion of the relevance of motivational theories follows a review of literature on decision procedures used for evaluating alternatives in situations of complexity. Hogarth and Reder (1986) explained that the paradigm of rational choice provides economics with a unity that is lacking in psychology. In the study of choice behavior, the two disciplines differ concerning scope of phenomena, object of study, and data considered relevant. Psychologists are interested in different types of individual process data. Despite these differences, the study indicated that each discipline could benefit from considering the alternative perspective.

Simon (1986) and Smith (1991) revealed the relationship between rationality and psychology. Simon (1986) asserted that the assumption that an individual maximizes subjective economic rationality provides only a small part of the premise in economic reasoning, and often not the essential part. The remainder of 
the premise is auxiliary empirical assumptions about individual's utilities, beliefs, expectations, and the like. Making these assumptions correctly requires an empirically founded theory of choice that specifies what information decision makers use and how they actually process it. This behavioral empirical base is largely lacking in contemporary economic analysis, and formulating it is essential for enhancing the explanatory and predictive power of economics. Smith (1991) believed a problem existed between economic theory and the falsifying evidence of psychology. Most standard theory provides a correct first approximation in predicting motivated behavior in laboratory experimental markets, but the theory is incomplete, particularly in articulating convergence processes in time and in ignoring decision cost. Furthermore, Anderson and Goldsmith (1994) dealt with the forecasting based on a psychological variable. Aftalion was the pioneer in using psychological factors in exchange rate determination (Baudin (1957)). Aftalion was the first to pay attention to the psychological impact in the foreign exchange market. However, no further empirical research has been done due to the fact that the quantifying of qualitative data is not easily feasible. Hopper (1997) described the importance of psychological impact in economic analysis. Hopper (1997) minutely analyzed market sentiment in the exchange rate determination. The news about the fundamentals can be defined as the difference between what market participants expect the fundamentals to be and what the fundamentals actually are once their values are announced. Hopper (1997) insisted that the alternative view is that exchange rates are determined, at least in the short-run period of less than two years, by the market sentiment. Under this view, the exchange rate is the result of a self-fulfilling prophecy. The participants in the foreign exchange market expect a currency to be a certain level in the future. When they act on their expectations, it ends up at the predicted level confirming their expectations. So it seems reasonable to try to understand the psychology of the foreign exchange market to improve forecasts of the short-run exchange rate determination.

\section{Theoretical Background}

\section{A. Forming Psychological Variable}

The basic idea in analyzing the psychological impact of the exchange rate determination is the transformation of qualitative data to a quantitative one. Frey and Eichenberger (1991) are the pioneers in this field of study. Frey and Eichenberger (1991) insist that cognitive psychology and experimental economics 
indicate that under identifiable conditions individuals do not act in an economically rational way. Also, economic markets do not fully eliminate anomalies in the aggregation process. Moreover, institutions can partially be interpreted as endogenously emerging as a result of individuals demands to cope with anomalies. According to Frey and Eichenberger (1991), psychological impact is shown in through diversified aspect. Such as reference point effect, sunk cost effect, endowment effect, framing effect, availability bias, representativeness bias, opportunity cost effect, and certainty effect. Based upon this, Fishbein and Ajzen (1975) developed the detailed formula of equation (1), and it enables to empirical analysis in this field.

$$
B \fallingdotseq B I=\left(\sum_{i=1}^{n} b_{i} e_{i}\right) w_{i}+\left(\sum_{j=1}^{N} N B_{j} M C_{j}\right) w_{j}
$$

where, $B$ : overt behavior

$B I$ : behavioral intentions

The equation (1) consists of a few coefficients. The $b_{i}$ is the consumer's view of the likelihood that performing the activity will result in the consequence $i$. The $e_{i}$ is the consumer's evaluation of outcome $i$ 's goodness or badness. The $N B_{j}$ is the person's assessment of whether referent $j$ thinks it should chose to undertake the activity. The $M C_{j}$ is the person's motivation to comply with referent $j$ 's opinion. The $n$ is the number of salient beliefs the person holds about performing the activity. As Miller (1956) asserted, the major group $\mathrm{i}$ in forming $\mathrm{BI}$ is usually assumed to be $7 \pm 2$. The $N$ is the number of other people whose opinions matter to the decision maker in the context question. The $w_{i}$ and $w_{j}$ are the weights that the analysis may estimate empirically using regression techniques, respectively.

\section{B. Application to Exchange Rate Determination}

The key exchange rate in the foreign exchange market in Korea is, of course, the U.S. Dollar. Therefore, understanding the determination of the U.S. Dollar is necessary to figure out the Korean foreign exchange market. Equation (1) can be modified to comply with exchange rate determination. $P S Y_{t}$ in equation (2) is an information matrix which captures the psychological impact of the U.S. Dollar on the foreign exchange market. The $b_{i}$ in equation (1) can be replaced by $D \cdot \Delta E X_{i}$, where $D$ is a dummy variable obtained from the news about economic fundamentals, and $\Delta E X_{i}$ is the first-differenced variable of the exchange rate in major group $i$. The $e_{i}$ 
could be set to 1 because the goodness or badness of the news is already reflected in the direction of its volatility. Also, $N B_{j} M C_{j}$ in equation (1) can be replaced by $D \cdot \Delta E X_{i}$, the first-differenced variable of the exchange rate in minor group $j$, in forming a psychological variable. The weights $w_{i}$ and $w_{j}$ can be replaced by the correlation between the U.S. Dollar and the first-differenced exchange rates. The weighted average is used by the $\overline{X_{w}}=\frac{\sum w_{i} X_{i}}{\sum w_{i}}$ scheme. Following Miller (1956), the number of $n$ is 5,7 , and 9 , respectively. It may provide an optimal number of major group. Equation (1) is reorganized as

$$
P S Y_{t}=\left(\sum_{i=1}^{n} D \cdot \Delta E X_{i t}\right) w_{i}+\left(\sum_{j=1}^{N} D \cdot \Delta E X_{j t}\right) w_{j}
$$

In equation (2) all the behavior for psychological impact created in the foreign exchange market toward the U.S. Dollar are included in the formula.

\section{1) Non-Economic Fundamental Factor}

To formulate a dummy variable which induces psychological impact, news about economic fundamentals that is not directly related to fundamental macroeconomic variables is used. The dummy variable comes from news about economic fundamentals which has sufficient impact to generate psychological information. The number of news items is summarized in Table 1. The number of news items from January 1997 to June 1997 is comparatively low. But, it has sharply increased since then, and it reached a high of 10 items in November 1997. The number of news items about economic fundamentals is concentrated after July 1997. This is because the economic crisis was initiated at this time.

Table 1. Number of news items about economic fundamentals

\begin{tabular}{|c|c|c|c|c|c|}
\hline Month & No. of Events & Month & No. of Events & Month & No. of Events \\
\hline 1997. 1 & 4 & 1997.11 & 10 & 1998. 9 & 6 \\
\hline 1997. 2 & 0 & 1997. 12 & 8 & 1998.10 & 5 \\
\hline 1997. 3 & 4 & 1998. 1 & 9 & 1998.11 & 6 \\
\hline 1997. 4 & 0 & 1998. 2 & 8 & 1998. 12 & 5 \\
\hline 1997. 5 & 4 & 1998. 3 & 6 & 1999. 1 & 5 \\
\hline 1997. 6 & 1 & 1998. 4 & 3 & 1999. 2 & 7 \\
\hline 1997. 7 & 5 & 1998. 5 & 8 & 1999. 3 & 6 \\
\hline 1997. 8 & 4 & 1998. 6 & 6 & 1999. & 6 \\
\hline 1997. 9 & 4 & 1998. 7 & 7 & 1999. 5 & 4 \\
\hline 1997. 10 & 5 & 1998. 8 & 7 & 1999. 6 & 8 \\
\hline
\end{tabular}




\section{2) Selecting Exchange Rates}

The number of officially transacting foreign exchange rates is 29 , including the U.S. Dollar, in Korea. Except for the U.S. Dollar, 28 of the first-differenced exchange rates are counted in forming a psychological information matrix. Depending upon the degree of correlation between the U.S. Dollar and the major group $\mathrm{i}$ is selected. The correlations are calculated by the first-differenced variables. In general, substitution among the exchange rate existed. The correlation can be replaced as a substitution factor. The weights $\omega_{i}$ and $\omega_{j}$ are replaced by using the correlation with the firstdifferenced U.S. Dollar. Daily data will be used for this analysis, and the source of the data is the Bank of Korea.

\section{3) Exchange Market Clearance and Psychological Hypothesis}

To evaluate psychological hypothesis in the foreign exchange market, rational expectation could be adopted to identify the foreign exchange market clearance. In this framework, it can be assumed that the psychological impact enables it to clear the market. It implies that the deviation will disappear or be taken care of by the psychological impact. It is assumed that the U.S. Dollar in the foreign exchange market is solely cleared by the psychological variable. According to Maddala (1992), rational expectation can be illustrated as follows.

$$
y_{t}^{*}-y_{t-1}^{*}=\lambda\left(y_{t-1}-y_{t-1}^{*}\right)
$$

where, $y_{t}^{*}$ : variable with rational expectation

$y_{t-1}^{*}:$ the first-differenced variable of observations

$\lambda$ : speed of adjustment

In equation (3), the $\lambda$ is in a range of $0<\lambda<1$. It gets a higher value if $y_{t}^{*}$ and $y_{t-1}$ approach faster. Also, prediction error can be expressed like equation (4). Statistical characteristics of define the rational expectation.

$$
\begin{gathered}
\varepsilon_{t}=y_{t}-y_{t}^{*} \\
E\left[e_{t}\right]=0
\end{gathered}
$$

Empirically, the rational expectation is characterized by the estimated coefficient $\alpha$ and statistical characteristics of $\varepsilon_{t}$ in equation (5). If the market is sufficiently satisfied with the rational expectation, then $\hat{\alpha}$ approached to a unity, and $\varepsilon_{t}$ is applicable to identically independently distributed or Gaussian white noise. 


$$
y_{t}=\alpha y_{t}^{*}+\varepsilon_{t}
$$

The most crucial factor is the definition of $y_{t}^{*}$ in the following equation (6). Here, $I_{t}$ is an information matrix which contains all the information to generate the rational expectation value, $y_{t}^{*}$. To generate $y_{t}^{*}$ or expected value, conditional probability of $y_{t}$ is conditioned by lagged information matrix. Equation (2) could be a psychological information matrix generating the expected value of the key exchange rate, in this case, the U.S. Dollar.

$$
y_{t}^{*}=E\left[y_{t} \mid I_{t-1}\right]
$$

\section{4) Econometric Methodology}

The data obtained from the foreign exchange market is commonly has heteroscedasticity in it. It implies that the information at $t-n$ period in the data is easily transferred to the next period. Also, uncertainty in the market is highly observed. The ARCH (Autoregressive Conditional Heteroscedasticity) model was introduced into econometric literature by Engle (1982) and was subsequently generalized by Bollerslev (1986) who proposed the generalized ARCH or GARCH (Generalized Autoregressive Conditional Heteroscedasticity) model. The development of the ARCH model by Engle (1982) and the GARCH model by Bollerslev (1986) enabled economists to figure out the foreign exchange market. The GARCH model incorporated infinite lagged variables in the analysis. Also, the GARCH-M model explains that conditional heteroscedasticity is generated based upon the mean. It implies that the model assumes a non-zero mean of the data.

Other related models, where the conditional variance of $\varepsilon_{t}$ is used as one of the regressors explaining the conditional mean of $y_{t}$, have also been suggested in the literature and are known as ARCH-M or GARCH-M model (Engle et al. (1987) and Bollerslev et al. (1992)). The various members of the GARCH and GARCH-M models can be written as follows.

$$
y_{t}=\beta^{\prime} x_{t}+\gamma h_{t}^{2}+\varepsilon_{t}
$$

where,

$$
h_{t}^{2}=V\left[\varepsilon_{t} \mid \Omega_{t-1}\right]=E\left[\varepsilon_{t}^{2} \mid \Omega_{t-1}\right]=\alpha_{0}+\sum_{i-1}^{a} \alpha_{i} \varepsilon_{t-i}^{2}+\sum_{j=1}^{p} \beta_{i} h_{t-j}^{2}
$$

and $\Omega_{t-1}$ is the information set at time $t-1$, containing at least the observations of 
$x_{t}$ and on lagged values of $y_{t}$ and $x_{t}$. Namely $\Omega_{t-1}$ is equal to $\left(x_{t}, x_{t-1}, x_{t-2}, \ldots\right.$, $\left.y_{t-1}, y_{t-2}, \ldots\right)$. The unconditional variance of $\varepsilon_{t}$ is constant because $V\left[\varepsilon_{t}\right]=$ $\lim _{s \rightarrow \infty} E\left[e_{t+s}^{2} \mid \Omega_{t-1}\right]$ and is formulated by

$$
V\left[\varepsilon_{t}\right]=\sigma^{2}=\frac{a_{0}}{1-\sum_{i=1}^{q} \alpha_{i}-\sum_{j=1}^{p} \beta_{i}}>0
$$

and the necessary condition for equation (7) to have a stationary covariance is given by

$$
\sum_{i=1}^{q} \alpha_{i}+\sum_{j=1}^{p} \beta_{i}<1
$$

In addition to the restrictions in equations (9) and (10), Bollerslev (1986) also assumes $\alpha_{i} \geq 0, i=1,2, \ldots, q$ and $\beta_{i} \geq 0, i=1,2, \ldots, p$. Although these additional restrictions are sufficient for the conditional variance to be positive, they are not necessary (Nelson and Cao (1992)). It also has to be satisfied that other variables could influence $h_{t}^{2}$.

$$
h_{t}^{2}=\omega+\sum_{i-1}^{q} \alpha_{i} \varepsilon_{t-i}^{2}+\sum_{j=1}^{q} \beta_{i} h_{t-j}^{2}+\mu_{i}
$$

The $\mu_{t}$ is a vector of covariance with stationary variables in $\Omega_{t-1}$.

\section{Empirical Results}

\section{A. Bubble or Psychology?}

As long as economic variables deviate from their fundamental values, it has to be defined whether the source of the deviation comes from a bubble or any other factor, such as psychological impact. The analysis on the bubbles in economic variables was performed by Ohanian (1996), Diba and Grossman (1988). Ohanian (1996) presented an analysis of the volatility of security prices to identify the bubbles. The research looked at whether movements in asset prices reflect changes in the fundamental value of the assets or whether these extreme price changes might be associated with changes in market psychology that may not be related to business conditions. The bubbles are defined as any deviation of the asset price from its fundamental value. However, certain types of bubbles can be difficult to 
explain in a sensible way because they are similar to Ponzi schemes. Ohanian (1996) introduced variance bounds tests which were originally developed by Shiller (1989). The test compares the volatility of the observed security price with the volatility of the fundamental price. Ohanian (1996) even suggested the test could be applicable to bond and foreign exchange markets. However, this practice leads to difficulties in evaluating whether market fundamentals are consistent with prices. On the other hand, Diba and Grossman (1988) insisted that the growth rate trend should be counted. First of all, the revealed deviation from the fundamental values in the exchange market has to be characterized because the bubbles and the psychological impact are shown as the same format. Depending upon the daily data availability, the interest rate is selected as a representative variable of the fundamental ones. If there exists any relationship in the long-run, the bubble hypothesis can be tentatively excluded, and the deviation should be counted as psychological impact. To identify it, Figure 1 and 2 depict the trend of level and

Figure 1. Trend of the U.S. Dollar and Interest Rates (Level).
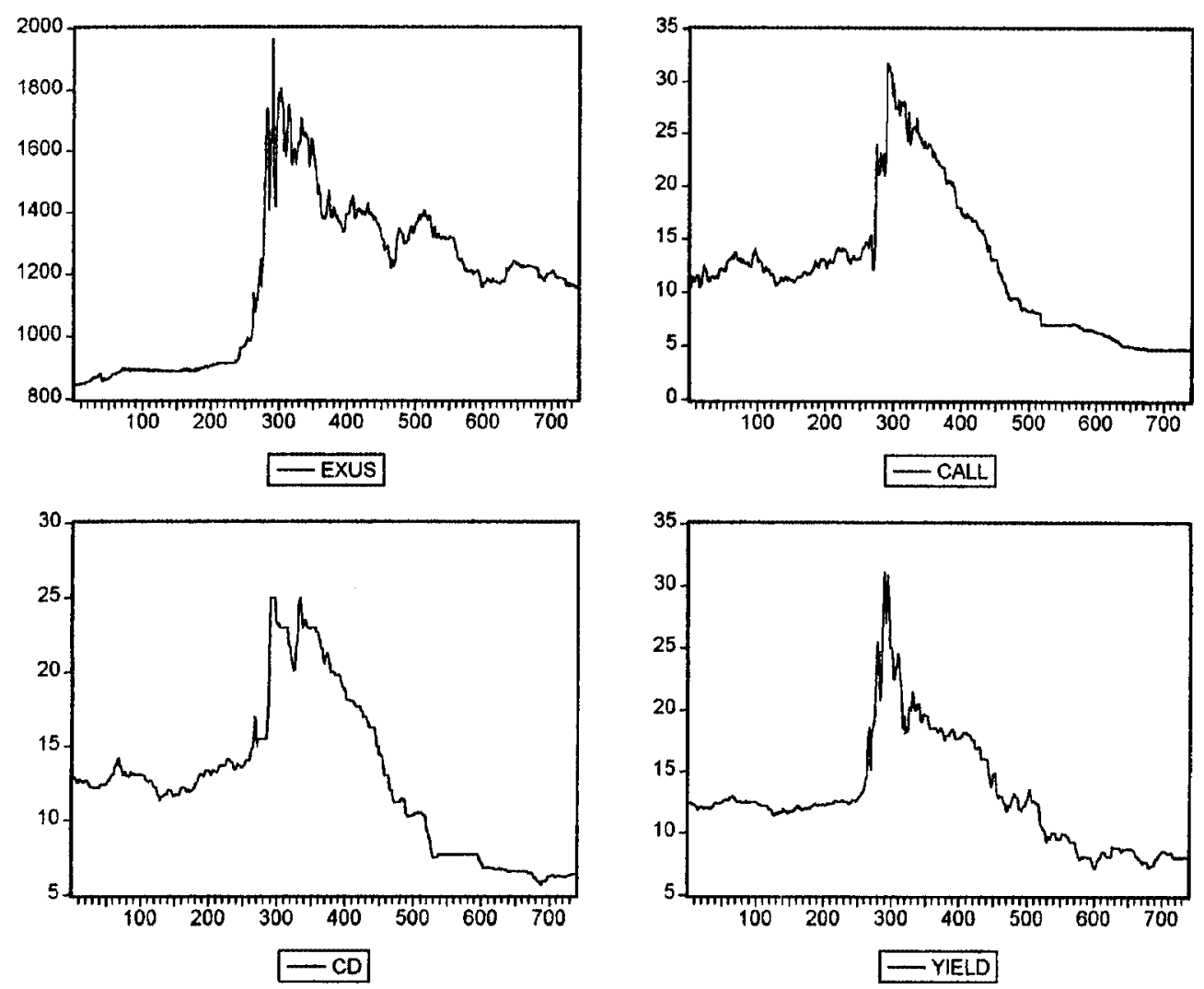
the first-differenced of Won per the U.S. Dollar, and short-run (call market), midrun $(\mathrm{CD})$, and long-run (yield on equity) interest rates, respectively.

Figure 1 depicts the trend of the level, and Figure 2 shows the trend of the firstdifferenced. As shown in Figures 1 and 2, all the trends have the same shapes. It indicates that the exchange rate moves upward as interest rates go up and vice versa. In other words, the exchange rate is depreciated when interest rates are rising up. Following the monetary approach on exchange rate determination, the exchange rate has to be appreciated when the interest rate goes up. Once this happens, the capital inflows to the home country to get the benefit from the increasing in the interest rate, and accordingly the home currency changes to a strong money. The Korean case seems to be opposite of this proposition. The Keynesian approach explains that if the exchange rate goes up, the economic activities in the domestic market slowdown because of reduced investment due to

Figure 2. Trend of the U.S. Dollar and Interest Rates (First Differenced).
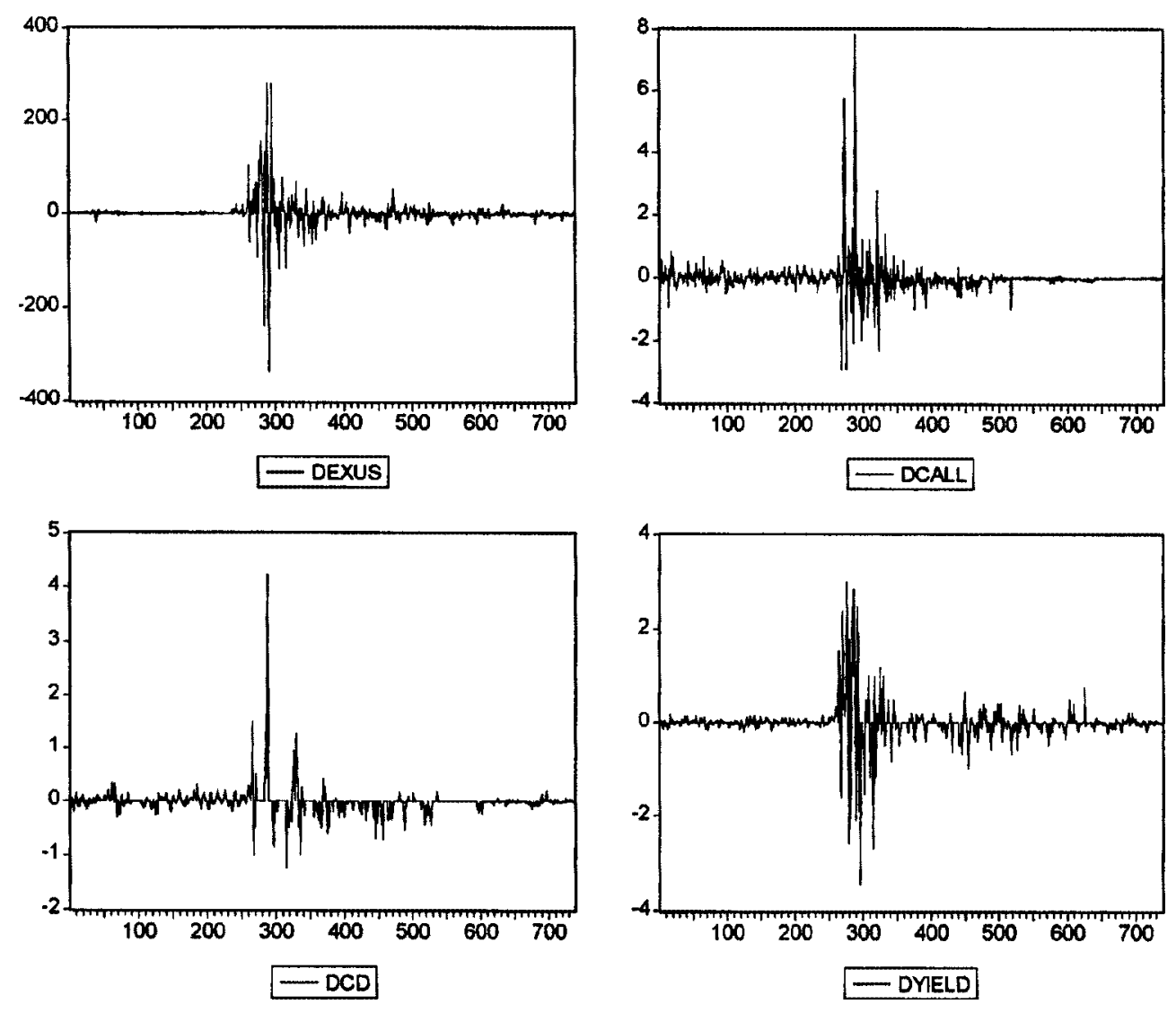
higher capital cost. The loss of competitiveness of the home country's products follows and, tentatively the home currency is depreciated. Brief review concludes that the Korean exchange market closely followed the Keynesian proposition, regardless of the short-run, mid-run, and long-run. ${ }^{1}$ Therefore, it can be concluded that there does not exist the bubbles in the Korean foreign exchange market because the exchange rate has a steady relationship with fundamental macroeconomic variables. If the deviation exists, it comes from another factor and not bubbles. Also, it allowed the study to focus on the psychological impact causes.

\section{B. The Impact of Psychological Information}

To figure out psychological impact, the information matrix which contains psychological factor has to be set up. The information matrix can be derived by using equation (2). Figure 3 shows the shapes of the information matrix with psychological impact. The psychological impact is abstracted from the fluctuation of $\triangle E X U S_{t}$.

Following Miller(1956), $\triangle E X U S_{t}$ and the three cases of psychological information matrix are analyzed. For the specific cases, a high level of psychological impact is chosen. They are based on $\left(\frac{P S Y}{\Delta E X U S_{t}}\right)>2$, and 17 cases were selected. In these cases, the psychological impact is two times stronger compared with the changing of $\triangle E X U S_{t}$ in an absolute value. It implies that the psychological impact was too strong in these cases. The direction of the $\triangle E X U S_{t}$ change and the psychological information matrix is randomly alternated. There does not exist a unique solution, and the direction is not matched. It looks like the supply and demand sides are affected in different ways. It can be assumed that the positive psychological impact brings an increase in $\left(\frac{\$}{\$}\right)$ and means it is depreciated. If the foreign exchange market faces a positive psychological impact, the demand for the U.S. Dollar will increase and it changes to a strong money. Whereas, the Korean Won changes to a weak money, or the Korean Won is depreciated. As far as the supply side is concerned, if a positive psychological impact induces a change in the exchange market, holding the U.S. Dollar brings a benefit. It accordingly leads to a decreasing in the supply of the U.S. Dollar. Altogether, demand and supply sides may have the same direction. Definitely a

'The results obtained by residual based method of cointegration technique (ADF and PP tests) support it. The U.S. Dollar and short-run, mid-run, and long-run interest rates are represented as I(1) series. The cointegration technique by Johansen-Juselius methodology reveals that there exists cointegrating vector in each case, as well. 
Figure 3. Psychological Information.
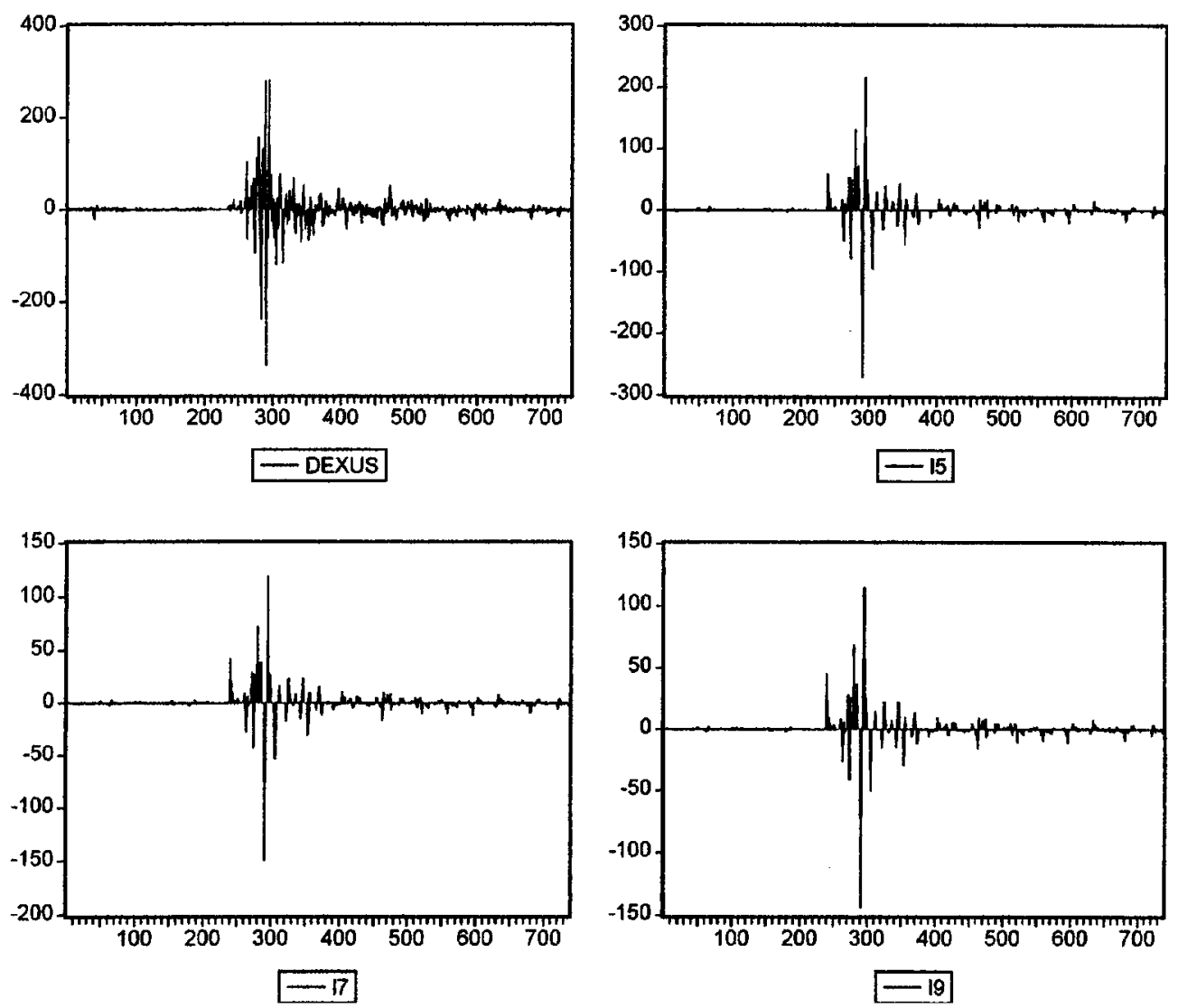

negative psychological impact will work the other way around. In Table 2, 11 out of 17 cases follow this manner. It is tentatively concluded that the impact of psychological factors is not easily characterized.

During the entire period of the analysis, the highest deviations between $\triangle E X U S_{t}$ and the psychological information matrix, where both $\triangle E X U S_{t}$ and the psychological matrix drastically fluctuated were on December 27, 1997(-) and on January 3, 1998(+). These cases are in Figure 4. Figure 4 depicts from November 1, 1997 to April 30, 1998 which is a high fluctuation period. The psychological impacts are highly fluctuated in this period. $P S Y_{t}$ and $\triangle E X U S_{t}$ both fluctuated, but the deviation between them is not that serious.

Most of psychological impact was reflected in the changing of $\triangle E X U S_{t}$, and it is in Figure 5. It was recorded on August 22, 1997. On that day, the news about economic fundamentals called "foreign credit status is in a severe condition". The date was the beginning of the economic crisis, and therefore it seems to have 
Table 2. Some Special Cases of Psychological Information

\begin{tabular}{|c|c|c|c|}
\hline Days & Events & $\begin{array}{l}\text { Psychological } \\
\text { Impact }\end{array}$ & $\triangle E X U S_{t}$ \\
\hline 97. 1.8 & $\begin{array}{l}\text { Committee for Monetary Reformation is } \\
\text { established }\end{array}$ & + & - \\
\hline 97. 3.21 & - Sammi Co. is bankrupted & - & - \\
\hline 97. 7.4 & $\begin{array}{l}\text { - Interest rate control / restrictions eliminated } \\
\text { on short-run savings deposit set to free } \\
\text {. Price for gold in the world market is drastically } \\
\text { corrupted }\end{array}$ & + & - \\
\hline 97.7 .11 & - Baht crisis in Thailand is widespread & + & + \\
\hline 97.7 .16 & $\begin{array}{l}\text { - Bankruptcy of Kia Group is pending } \\
\text { - Domestic fund market is tightened }\end{array}$ & - & - \\
\hline 97.8 .12 & - Fund for merchant banks is heavily depleted & - & - \\
\hline 97.8 .22 & . Foreign credit status is in a severe condition & + & - \\
\hline 97. 9.12 & $\begin{array}{l}\text { Daenong Co. requests to be under juridical } \\
\text { management }\end{array}$ & + & - \\
\hline 98.3 .31 & $\begin{array}{l}\text { Foreign currency trading restrictions are } \\
\text { completely eliminated, and it will take effect by } \\
\text { July }\end{array}$ & - & - \\
\hline 98.5 .7 & $\begin{array}{l}\text { Korean government and IMF agree to cut interest } \\
\text { rates }\end{array}$ & - & + \\
\hline 98.9. 2 & $\begin{array}{l}\text { Dow Jones Index collapsed and world financial } \\
\text { market has severe fluctuation }\end{array}$ & + & + \\
\hline 98.11 .6 & $\begin{array}{l}\text { Fund support for mid-sized firms is tightened } \\
\text { - Agreement for free trade between Korea and Chile } \\
\text { is established }\end{array}$ & + & + \\
\hline 98. 11.28 & Intern for major companies is initiated again & - & - \\
\hline 99.4 .7 & - Public enterprises record an 11 trillion Won deficit & + & + \\
\hline 99.5 .20 & $\begin{array}{l}\text { Price for gold lowest in the previous two decades } \\
\text { Dollar is hiked and Yen per Dollar records } 124\end{array}$ & - & - \\
\hline 99.6 .22 & $\begin{array}{l}\text { KOSPI records } 860 \text { points, and it is the highest in } \\
\text { the previous three decades }\end{array}$ & - & + \\
\hline 99.6 .29 & $\begin{array}{l}\text { - Debate on the revaluation of the Won is } \\
\text { undertaken } \\
\text { - KOSPI records more than } 900 \text { points }\end{array}$ & - & - \\
\hline
\end{tabular}

brought a relatively strong impact to the foreign exchange markets. It recorded $-25.1870,-19.0392$, and -15.1430 , respectively. It hits its upper limit and it was sufficient to judge as a psychological crisis.

\section{Preliminary Statistic of the Variables}

The preliminary statistics are evaluated and the results are summarized in Table 
Figure 4. Highest Psychological Volatility.
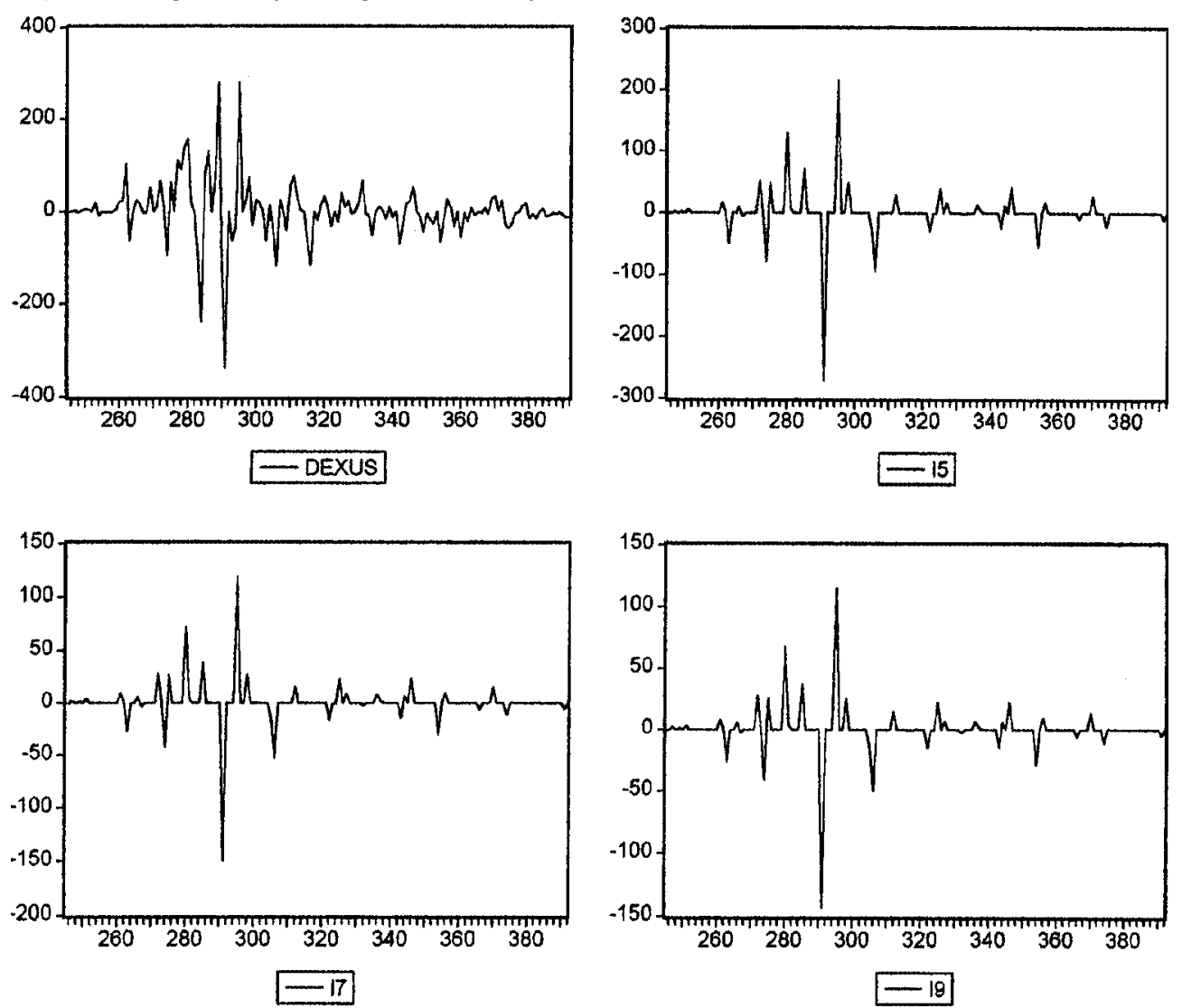

3 to identify statistical characteristics of the variables. And whether the normal distribution is achieved or not for the variables is illustrated in Figure 6.

As these have shown, non-conditional distribution of all the variables is far from normal. The negative skewness shows a left-skewed, fat-tailed distribution. The Kurtosis is more than 3 in all the cases. It is a leptokurtic. The higher Jarque-Bera statistic also proves non-normality. It is an easily found volatility clustering phenomenon. To identify any existing serial correlation in the standardized residuals and squares of the standardized residuals, the Ljung-Box Q test for the serial correlation in the standardized residuals and the Ljung-Box $Q^{2}$ test for the squares of the standardized residuals are checked. It is approximately distributed as $\chi^{2}$ under the null hypothesis, and lower lags are mixed. However, $Q(10)$ and $Q^{2}(10)$ are rejected null hypotheses. It implies that the serial correlations exist in both cases. Therefore, the traditional econometric methodology easily misleads the result. It shows that the 
Figure 5. Psychological Crisis.
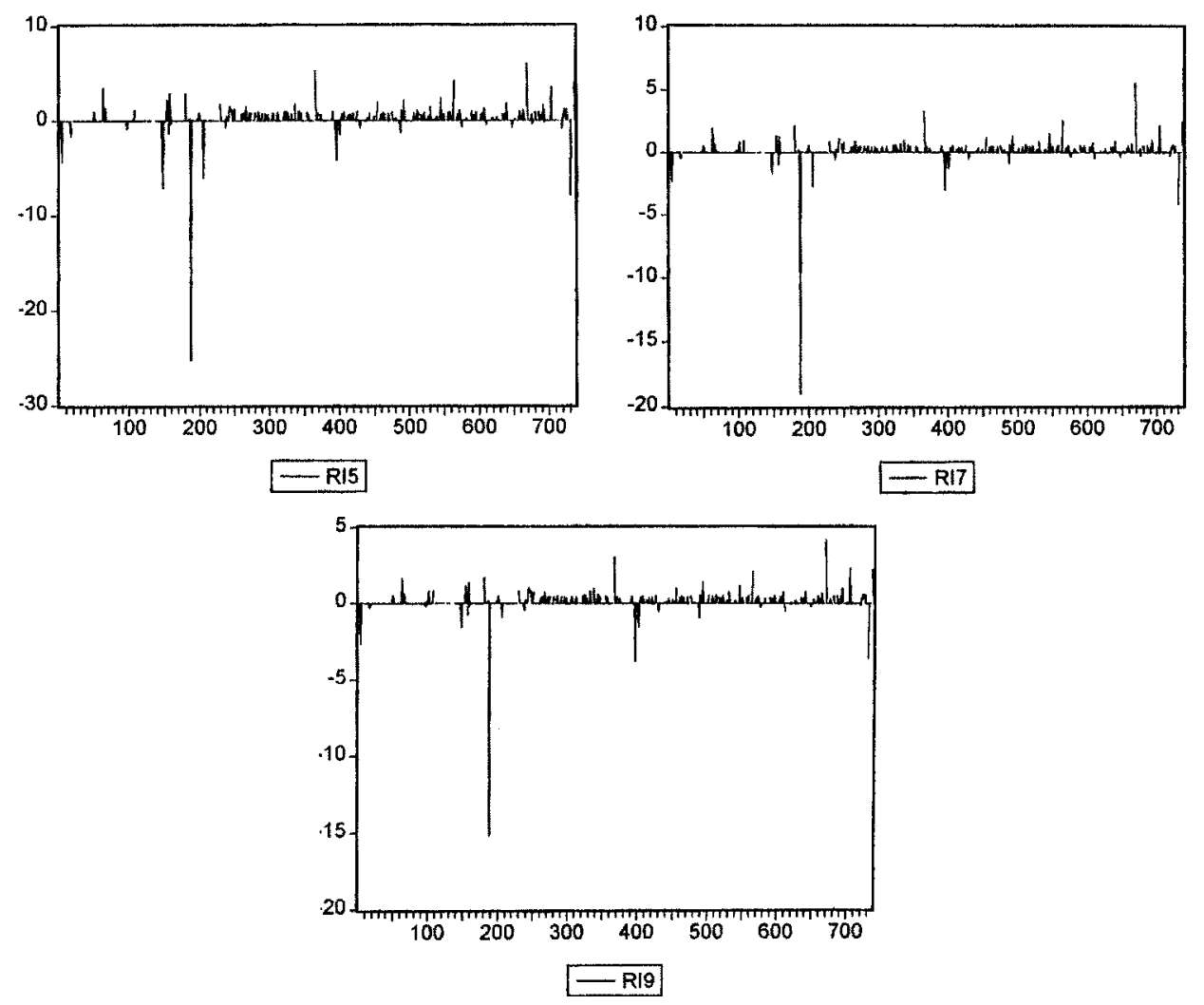

model which captures changing variance and covariance has to be selected. For this purpose, any econometric model which is applicable for conditional heteroscedasticity has to be taken care of. Also, for additional identification, the degree of differences and the stationarity is checked, and concluded that $\Delta E X U S_{t}$ and $\Delta E X U S_{t}^{p s y}$ are $\mathrm{I}(0)$. It implies that the level of both variables is I(1). Therefore, the $\operatorname{GARCH}(1,1)-\mathrm{M}$ model can be applied with a normal assumption.

\section{Estimation of Market Clearance by Psychological Variable}

According to Rhee (1997) neither the Keynesian nor the Monetarist approach explain the determination of the exchange rate in Korean foreign exchange markets. It means that any other factor besides the fundamental factor can provide a solution. Once the psychological information matrix is generated, the expected U.S. Dollar with psychological impact can be determined by executing the conditional probability of the first-differenced U.S. Dollar based on lagged information matrix. It is shown in equation (12). Based on the psychological informa- 
Table 3. Preliminary Statistic of the Variables

\begin{tabular}{|c|c|c|c|c|}
\hline Variables & $\Delta E X U S_{t}$ & $P I 5_{t}$ & $P I 7_{t}$ & $P I 9_{t}$ \\
\hline Mean & 0.422 & 0.424 & 0.424 & 0.424 \\
\hline Std. Dev. & 28.864 & 0.995 & 0.979 & 0.960 \\
\hline MAX & 280.60 & 13.85 & 13.54 & 13.28 \\
\hline MIN & -337.20 & -16.40 & -16.06 & -15.69 \\
\hline Skewness & -0.105 & -2.695 & -2.627 & -2.527 \\
\hline Kurtosis & 60.852 & 166.198 & 163.308 & 161.542 \\
\hline Jarque-Bera & 102916.3 & 819872.6 & 791086.9 & 773705.0 \\
\hline$Q(1)$ & $\begin{array}{c}17.884 * \\
{[0.00]}\end{array}$ & $\begin{array}{l}0.004 \\
{[0.95]}\end{array}$ & $\begin{array}{l}0.001 \\
{[0.98]}\end{array}$ & $\begin{array}{l}0.001 \\
{[0.98]}\end{array}$ \\
\hline$Q(2)$ & $\begin{array}{c}32.910 * \\
{[0.00]}\end{array}$ & $\begin{array}{c}0.564 \\
{[0.75]}\end{array}$ & $\begin{array}{l}0.516 \\
{[0.77]}\end{array}$ & $\begin{array}{c}0.528 \\
{[0.77]}\end{array}$ \\
\hline$Q(3)$ & $\begin{array}{c}38.141 * \\
{[0.00]}\end{array}$ & $\begin{array}{c}3.777 \\
{[0.29]}\end{array}$ & $\begin{array}{c}3.556 \\
{[0.31]}\end{array}$ & $\begin{array}{c}3.536 \\
{[0.32]}\end{array}$ \\
\hline$Q(10)$ & $\begin{array}{c}301.210 * \\
{[0.00]}\end{array}$ & $\begin{array}{c}107.050 * \\
{[0.00]}\end{array}$ & $\begin{array}{c}103.510 * \\
{[0.00]}\end{array}$ & $\begin{array}{c}101.560 * \\
{[0.00]}\end{array}$ \\
\hline$Q^{2}(1)$ & $\begin{array}{c}15.392 * \\
{[0.00]}\end{array}$ & $\begin{array}{c}0.007 \\
{[0.93]}\end{array}$ & $\begin{array}{c}0.009 \\
{[0.92]}\end{array}$ & $\begin{array}{l}0.009 \\
{[0.92]}\end{array}$ \\
\hline$Q^{2}(2)$ & $\begin{array}{c}110.800 * \\
{[0.00]}\end{array}$ & $\begin{array}{c}0.017 \\
{[0.99]}\end{array}$ & $\begin{array}{c}0.020 \\
{[0.99]}\end{array}$ & $\begin{array}{c}0.020 \\
{[0.99]}\end{array}$ \\
\hline$Q^{2}(3)$ & $\begin{array}{c}117.960 * \\
{[0.00]}\end{array}$ & $\begin{array}{c}0.185 \\
{[0.98]}\end{array}$ & $\begin{array}{c}0.180 \\
{[0.98]}\end{array}$ & $\begin{array}{c}0.176 \\
{[0.98]}\end{array}$ \\
\hline$Q^{2}(10)$ & $\begin{array}{c}445.450 * \\
{[0.00]}\end{array}$ & $\begin{array}{c}146.820 * \\
{[0.00]}\end{array}$ & $\begin{array}{c}144.800 * \\
{[0.00]}\end{array}$ & $\begin{array}{c}145.120 * \\
{[0.00]}\end{array}$ \\
\hline
\end{tabular}

Notes: 1) The figures inside parentheses are the number of lags, and inside brackets are the $p$-values.

2) $Q$ and $Q^{2}$ are Ljung-Box's test statistics for the serial correlation in the standardized residuals, and squares of the standardized residuals, respectively.

3) The critical values at $5 \%$ level for $\chi^{2}(1), \chi^{2}(2), \chi^{2}(3)$, and $\chi^{2}(10)$ are $3.84,5.99,7.81$, and 18.31 , respectively.

tion matrix, the conditional probability for $\triangle E X U S_{t}$ can be calculated as shown in equation (12). $\Delta E X U S_{t}^{p s y}$ is a projection of $\triangle E X U S_{t}$ with psychological impact.

$$
\Delta E X U S_{t}^{p s y}=E\left[\Delta E X U S_{t} \mid P S Y_{t-1}\right]
$$

Once $\Delta E X U S_{t}^{p s y}$ is obtained, the rational expectation can be applied to see if there exists market clearance by adapting the GARCH-M model. It is shown in 
Figure 6. Statistical Distribution of the Variable.
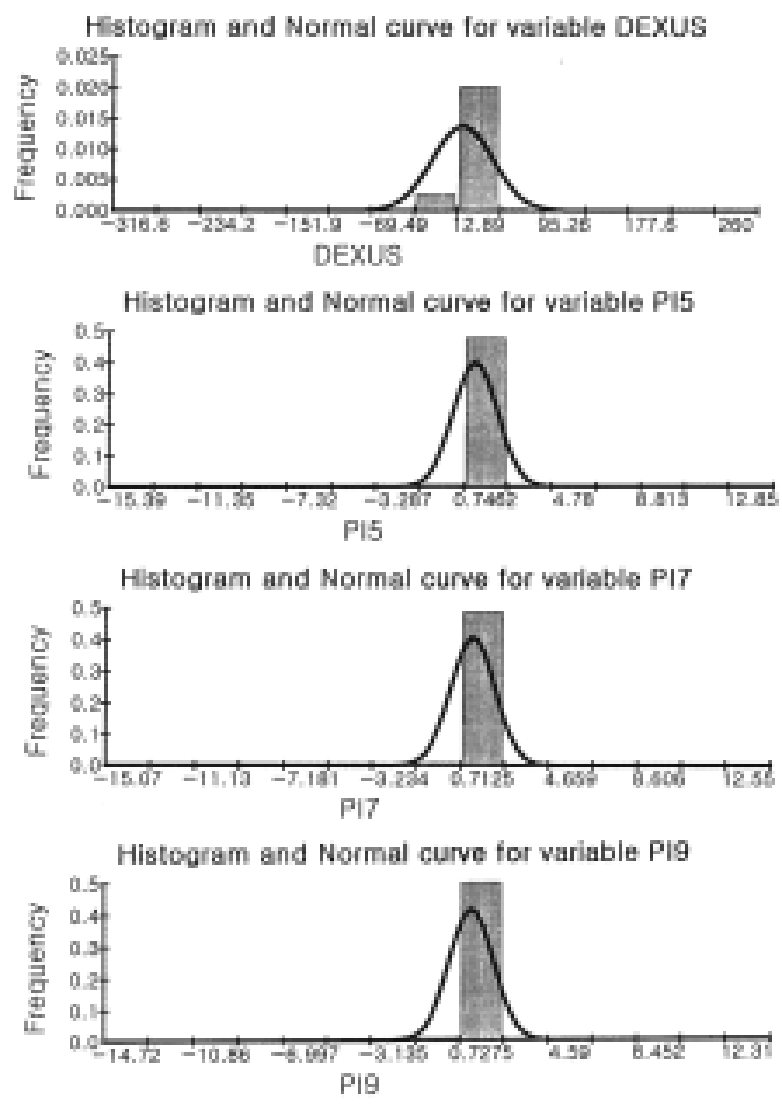

equations (13) and (14).

$$
\begin{gathered}
\Delta E X U S_{t}=\theta+\phi \Delta E X U S_{t}^{p s y} \mid+\varepsilon_{t} \\
h_{t}^{2}=\omega+\alpha \varepsilon_{t-1}^{2}+\beta h_{t-1}^{2}
\end{gathered}
$$

Here, the estimated coefficient of $\phi, \hat{\phi}$ is expected to be 1 as long as the exchange market is cleared. $\alpha$ and $\hat{\beta}$ represent the ARCH and GARCH factors, respectively. In general, $\hat{\omega}, \hat{\alpha}$, and $\hat{\beta}$ are expected to be positive. To be a strong stationarity, $\hat{\alpha}+\hat{\beta}<1$ has to be satisfied. To calculate maximum log likelihood function, BHHH (Berndt, Hall, Hall, and Hausman (1974)) algorithm is applied.

According to the results in Table 4, it is confirmed that $\hat{\phi}$ equals 1 . However, it calculated $0.7824,0.7584$, and 0.7293 , respectively for the entire period. It implies that the U.S. Dollar in the foreign exchange market is not cleared by the psychological impact. The period is subdivided every three months, and it cumulated until the 
exchange market is cleared. The 9 cases satisfied the market clearance condition. It also has to be mentioned that the adjustment of conditional heteroscedasticity is done using the GARCH channel rather than the ARCH. The ARCH component ranges from 0.0350 to 0.4371 , while the GARCH component distributes from 0.5848 to 0.8981 . The summary of empirical results by the GARCH(1,1)-M model is shown in Table 4 . As expected, $\hat{\omega}+\hat{\alpha}$, and $\hat{\beta}$ are positive. However, $\hat{\alpha}+\hat{\beta}<1$, is not satisfied

Table 4. Summary of Empirical Results

\begin{tabular}{|c|c|c|c|c|c|c|c|}
\hline \multirow{2}{*}{ Periods } & \multirow{2}{*}{$\begin{array}{l}\text { No. of } \\
\text { Group } i\end{array}$} & \multicolumn{6}{|c|}{ Estimated Coefficients } \\
\hline & & $\theta$ & $\phi$ & $\omega$ & $\alpha$ & $\beta$ & LR \\
\hline \multirow{3}{*}{$97.1-99.6$} & 5 & $\begin{array}{c}-0.1060 \\
(-2.18)^{* *}\end{array}$ & $\begin{array}{c}0.7824 \\
(2.55) * *\end{array}$ & $\begin{array}{c}0.2315 \\
(11.22)^{* *}\end{array}$ & $\begin{array}{c}0.3418 \\
(16.90)^{* *}\end{array}$ & $\begin{array}{c}0.7668 \\
(73.57)^{* *}\end{array}$ & -2458.48 \\
\hline & 7 & $\begin{array}{c}-0.1041 \\
(-2.21)^{* *}\end{array}$ & $\begin{array}{c}0.7584 \\
(2.61)^{* *}\end{array}$ & $\begin{array}{c}0.2300 \\
(11.42)^{* *}\end{array}$ & $\begin{array}{c}0.3425 \\
(16.90)^{* *}\end{array}$ & $\begin{array}{c}0.7667 \\
(73.64)^{* *}\end{array}$ & -2458.54 \\
\hline & 9 & $\begin{array}{c}-0.1012 \\
(-2.18)^{* *}\end{array}$ & $\begin{array}{c}0.7273 \\
(2.56)^{* *}\end{array}$ & $\begin{array}{c}0.2305 \\
(11.52)^{* *}\end{array}$ & $\begin{array}{c}0.3430 \\
(16.92)^{* *}\end{array}$ & $\begin{array}{c}0.7666 \\
(73.74)^{* *}\end{array}$ & -2458.72 \\
\hline \multirow{3}{*}{$97.7-98.3$} & 5 & $\begin{array}{c}-0.0551 \\
(-0.59)\end{array}$ & $\begin{array}{c}1.0137 \\
(2.16)^{* *}\end{array}$ & $\begin{array}{c}0.2638 \\
(5.39)^{* *}\end{array}$ & $\begin{array}{c}0.3527 \\
(10.85)^{* *}\end{array}$ & $\begin{array}{c}0.7828 \\
(44.34)^{* *}\end{array}$ & -841.98 \\
\hline & 7 & $\begin{array}{c}-0.0545 \\
(-0.59)\end{array}$ & $\begin{array}{c}1.0115 \\
(2.31)^{* *}\end{array}$ & $\begin{array}{c}0.2670 \\
(5.55)^{* *}\end{array}$ & $\begin{array}{c}0.3550 \\
(10.84)^{* *}\end{array}$ & $\begin{array}{c}0.7824 \\
(44.12)^{* *}\end{array}$ & -842.02 \\
\hline & 9 & $\begin{array}{c}-0.0518 \\
(-0.56)\end{array}$ & $\begin{array}{c}0.9656 \\
(2.25)^{* *}\end{array}$ & $\begin{array}{c}0.2679 \\
(5.78)^{* *}\end{array}$ & $\begin{array}{c}0.3554 \\
(10.89)^{* *}\end{array}$ & $\begin{array}{c}0.7825 \\
(44.07) * *\end{array}$ & -842.18 \\
\hline \multirow{3}{*}{$97.7-98.6$} & 5 & $\begin{array}{c}-0.0527 \\
(-0.80)\end{array}$ & $\begin{array}{c}0.9665 \\
(2.17)^{* *}\end{array}$ & $\begin{array}{c}0.2725 \\
(6.27)^{* *}\end{array}$ & $\begin{array}{c}0.3411 \\
(12.07) * *\end{array}$ & $\begin{array}{c}0.7804 \\
(48.37)^{* *}\end{array}$ & -1148.96 \\
\hline & 7 & $\begin{array}{c}-0.0510 \\
(-0.78)\end{array}$ & $\begin{array}{c}0.9452 \\
(2.32)^{* *}\end{array}$ & $\begin{array}{c}0.2716 \\
(6.64)^{* *}\end{array}$ & $\begin{array}{c}0.3404 \\
(12.08) * *\end{array}$ & $\begin{array}{c}0.7809 \\
(48.46)^{* *}\end{array}$ & -1149.04 \\
\hline & 9 & $\begin{array}{l}-0.049 \\
(-0.75)\end{array}$ & $\begin{array}{c}0.8828 \\
(2.22) * *\end{array}$ & $\begin{array}{c}0.2833 \\
(7.04)^{* *}\end{array}$ & $\begin{array}{c}0.3523 \\
(11.95)^{* *}\end{array}$ & $\begin{array}{c}0.7757 \\
(47.22)^{* *}\end{array}$ & -1149.26 \\
\hline \multirow{3}{*}{$97.7-98.9$} & 5 & $\begin{array}{c}-0.0562 \\
(-0.92)\end{array}$ & $\begin{array}{c}0.9879 \\
(2.35)^{* *}\end{array}$ & $\begin{array}{c}0.2552 \\
(6.50)^{* *}\end{array}$ & $\begin{array}{c}0.3042 \\
(13.02)^{* *}\end{array}$ & $\begin{array}{c}0.7945 \\
(55.46)^{* *}\end{array}$ & -1452.98 \\
\hline & 7 & $\begin{array}{c}-0.0537 \\
(-0.90)\end{array}$ & $\begin{array}{c}0.9503 \\
(2.48)^{* *}\end{array}$ & $\begin{array}{c}0.2564 \\
(6.95)^{* *}\end{array}$ & $\begin{array}{c}0.3051 \\
(12.99)^{* *}\end{array}$ & $\begin{array}{c}0.7942 \\
(55.31)^{* *}\end{array}$ & -1453.07 \\
\hline & 9 & $\begin{array}{c}-0.0494 \\
(-0.82)\end{array}$ & $\begin{array}{c}0.9028 \\
(2.43)^{* *}\end{array}$ & $\begin{array}{c}0.2556 \\
(7.22)^{* *}\end{array}$ & $\begin{array}{c}0.3036 \\
(13.03)^{* *}\end{array}$ & $\begin{array}{c}0.7951 \\
(55.49)^{* *}\end{array}$ & -1453.30 \\
\hline \multirow{3}{*}{$97.7-98.12$} & 5 & $\begin{array}{l}-0.1022 \\
(-1.78)^{*}\end{array}$ & $\begin{array}{c}1.0739 \\
(2.56)^{* *}\end{array}$ & $\begin{array}{c}0.2868 \\
(7.32)^{* *}\end{array}$ & $\begin{array}{c}0.3180 \\
(14.38)^{* *}\end{array}$ & $\begin{array}{c}0.7794 \\
(63.57)^{* *}\end{array}$ & -1707.61 \\
\hline & 7 & $\begin{array}{l}-0.1001 \\
(-1.77)^{*}\end{array}$ & $\begin{array}{c}1.0365 \\
(2.69)^{* *}\end{array}$ & $\begin{array}{c}0.2832 \\
(7.78)^{* *}\end{array}$ & $\begin{array}{c}0.3183 \\
(14.47)^{* *}\end{array}$ & $\begin{array}{c}0.7796 \\
(63.83)^{* *}\end{array}$ & -1707.72 \\
\hline & 9 & $\begin{array}{l}-0.0968 \\
(-1.85)^{*}\end{array}$ & $\begin{array}{c}0.9951 \\
(2.60)^{* *}\end{array}$ & $\begin{array}{c}0.2877 \\
(8.05)^{* *}\end{array}$ & $\begin{array}{c}0.3193 \\
(14.57)^{* *}\end{array}$ & $\begin{array}{c}0.7792 \\
(63.77)^{* *}\end{array}$ & -1707.95 \\
\hline
\end{tabular}

Notes : 1) The figure inside parentheses is a critical value for t-statistics.

2 ) $*$ is for $10 \%$, and $* *$ is for $5 \%$ significant levels.

3) The median lags, $-\log (2 / \beta)$ which capture the persistence of the psychological shocks ranges from 0.8006 to 1.2296 . 
Table 4. Continued

\begin{tabular}{|c|c|c|c|c|c|c|c|}
\hline \multirow{2}{*}{ Periods } & \multirow{2}{*}{$\begin{array}{l}\text { No. of } \\
\text { Group } i\end{array}$} & \multicolumn{6}{|c|}{ Estimated Coefficients } \\
\hline & & $\theta$ & $\phi$ & $\omega$ & $\alpha$ & $\beta$ & LR \\
\hline \multirow{3}{*}{$97.7-99.3$} & 5 & $\begin{array}{c}-0.093 \\
(-1.73)^{*}\end{array}$ & $\begin{array}{c}1.0577 \\
(2.49)^{* *}\end{array}$ & $\begin{array}{c}0.3166 \\
(7.41)^{* * *}\end{array}$ & $\begin{array}{c}0.3337 \\
(15.18)^{* *}\end{array}$ & $\begin{array}{c}0.7707 \\
(65.24)^{* *}\end{array}$ & -1939.33 \\
\hline & 7 & $\begin{array}{c}-0.089 \\
(-1.68)^{*}\end{array}$ & $\begin{array}{c}1.0111 \\
(2.60)^{* *}\end{array}$ & $\begin{array}{c}0.3108 \\
(7.88)^{* * *}\end{array}$ & $\begin{array}{c}0.3313 \\
(15.22)^{* *}\end{array}$ & $\begin{array}{c}0.7721 \\
(65.71)^{* *}\end{array}$ & -1939.42 \\
\hline & 9 & $\begin{array}{l}-0.0871 \\
(-1.65)^{*}\end{array}$ & $\begin{array}{c}0.9747 \\
(2.56) * *\end{array}$ & $\begin{array}{c}0.3209 \\
(8.11)^{* * *}\end{array}$ & $\begin{array}{c}0.3351 \\
(15.24)^{* *}\end{array}$ & $\begin{array}{c}0.7703 \\
(65.31)^{* *}\end{array}$ & -1939.68 \\
\hline \multirow{3}{*}{$97.7-99.6$} & 5 & $\begin{array}{c}-0.1058 \\
(-2.09) * *\end{array}$ & $\begin{array}{c}0.9941 \\
(2.33)^{* *}\end{array}$ & $\begin{array}{c}0.3795 \\
(7.79)^{* * *}\end{array}$ & $\begin{array}{c}0.3299 \\
(16.04)^{* *}\end{array}$ & $\begin{array}{c}0.7715 \\
(67.77)^{* *}\end{array}$ & -2161.03 \\
\hline & 7 & $\begin{array}{c}-0.1028 \\
(-2.07)^{* *}\end{array}$ & $\begin{array}{c}0.9489 \\
(2.48)^{* *}\end{array}$ & $\begin{array}{c}0.3738 \\
(8.13)^{* *}\end{array}$ & $\begin{array}{c}0.3284 \\
(16.13)^{* *}\end{array}$ & $\begin{array}{c}0.7725 \\
(68.50)^{* *}\end{array}$ & -2161.15 \\
\hline & 9 & $\begin{array}{c}-0.1006 \\
(-2.04)^{* *}\end{array}$ & $\begin{array}{c}0.9124 \\
(2.45)^{* *}\end{array}$ & $\begin{array}{c}0.3818 \\
(8.29)^{* * *}\end{array}$ & $\begin{array}{c}0.3309 \\
(16.14)^{* *}\end{array}$ & $\begin{array}{c}0.7711 \\
(68.15)^{* *}\end{array}$ & -2161.37 \\
\hline \multirow{3}{*}{$98.1-98.6$} & 5 & $\begin{array}{c}-0.0215 \\
(-0.18)\end{array}$ & $\begin{array}{c}-0.3551 \\
(-0.11)\end{array}$ & $\begin{array}{l}12.9635 \\
(3.37)^{* * *}\end{array}$ & $\begin{array}{l}0.0353 \\
(1.81)^{*}\end{array}$ & $\begin{array}{c}0.8974 \\
(54.41)^{* *}\end{array}$ & -668.30 \\
\hline & 7 & $\begin{array}{c}-0.0130 \\
(-0.10)\end{array}$ & $\begin{array}{c}-0.7549 \\
(-0.17)\end{array}$ & $\begin{array}{l}12.7991 \\
(3.49) * *\end{array}$ & $\begin{array}{c}0.035 \\
(1.86)^{*}\end{array}$ & $\begin{array}{c}0.8979 \\
(62.84) * *\end{array}$ & -668.28 \\
\hline & 9 & $\begin{array}{c}-0.0068 \\
(-0.06)\end{array}$ & $\begin{array}{c}-1.0304 \\
(-0.24)\end{array}$ & $\begin{array}{l}12.6929 \\
(3.47)^{* * *}\end{array}$ & $\begin{array}{l}0.0352 \\
(1.86)^{*}\end{array}$ & $\begin{array}{c}0.8981 \\
(63.25)^{* *}\end{array}$ & -668.25 \\
\hline \multirow{3}{*}{ 98.4-98.12 } & 5 & $\begin{array}{l}-0.1708 \\
(-1.77)^{*}\end{array}$ & $\begin{array}{c}0.9133 \\
(1.30)\end{array}$ & $\begin{array}{l}10.6516 \\
(2.20) * *\end{array}$ & $\begin{array}{c}0.4250 \\
(4.16)^{* *}\end{array}$ & $\begin{array}{c}0.5879 \\
(6.39)^{* *}\end{array}$ & -858.48 \\
\hline & 7 & $\begin{array}{l}-0.1590 \\
(-1.68)^{*}\end{array}$ & $\begin{array}{c}0.6450 \\
(0.87)\end{array}$ & $\begin{array}{l}10.5648 \\
(2.16)^{* * *}\end{array}$ & $\begin{array}{c}0.4323 \\
(4.22)^{* *}\end{array}$ & $\begin{array}{c}0.5848 \\
(6.37)^{* * *}\end{array}$ & -858.50 \\
\hline & 9 & $\begin{array}{l}-0.1421 \\
(-1.69)^{*}\end{array}$ & $\begin{array}{l}0.2219 \\
(1.23)\end{array}$ & $\begin{array}{c}10.10 \\
(1.99)^{* * *}\end{array}$ & $\begin{array}{c}0.4371 \\
(4.31)^{* * *}\end{array}$ & $\begin{array}{c}0.5873 \\
(6.45)^{* *}\end{array}$ & -858.52 \\
\hline \multirow{3}{*}{$98.7-99.6$} & 5 & $\begin{array}{l}-0.1980 \\
(-1.79)^{*}\end{array}$ & $\begin{array}{l}1.3551 \\
(1.41)\end{array}$ & $\begin{array}{c}4.4258 \\
(4.93)^{* *}\end{array}$ & $\begin{array}{c}0.4108 \\
(5.71)^{* *}\end{array}$ & $\begin{array}{c}0.5985 \\
(11.64)^{* *}\end{array}$ & -996.73 \\
\hline & 7 & $\begin{array}{l}-0.1888 \\
(-1.72)^{*}\end{array}$ & $\begin{array}{l}1.1959 \\
(1.22)\end{array}$ & $\begin{array}{c}4.3791 \\
(4.83)^{* *}\end{array}$ & $\begin{array}{c}0.4106 \\
(5.68)^{* *}\end{array}$ & $\begin{array}{c}0.5997 \\
(11.66)^{* *}\end{array}$ & -996.81 \\
\hline & 9 & $\begin{array}{c}-0.1858 \\
(-1.63)\end{array}$ & $\begin{array}{l}1.1680 \\
(1.00)\end{array}$ & $\begin{array}{c}4.4115 \\
(4.80)^{* *}\end{array}$ & $\begin{array}{c}0.4152 \\
(5.62)^{* *}\end{array}$ & $\begin{array}{c}0.5969 \\
(11.64)^{* *}\end{array}$ & -996.83 \\
\hline
\end{tabular}

Notes : 1) The figure inside parentheses is a critical value for t-statistics.

2 ) $*$ is for $10 \%$, and $* *$ is for $5 \%$ significant levels.

3) The median lags, $-\log (2 / \beta)$ which capture the persistence of the psychological shocks ranges from 0.8006 to 1.2296

in all cases. It implies that the model does not hold a strong stationarity. The results weakly support the psychological hypothesis in the determination of the U.S. Dollar in Korean foreign exchange markets. Also, the number of major group $i$ does not really matter. It shows that Miller's theorem does not work in this analysis. 


\section{E. Forecastbility}

Forecasting with the rational expectation framework based on psychological impact was done by Anderson and Goldsmith (1994) to evaluate the decision making process. Rationality and psychology were understood as a source for an unbiased forecast in the framework, and the forecasting error is defined by the difference between evaluation at time $t$ and prediction at time $t-2$. Anderson and Goldsmith (1994) also constructed an error-learning model and applied it to their empirical studies. The analysis revealed systematically biased decision making by decision makers. In general, their decision is overly optimistic. Past learning is of little consequence to the accuracy of forecasts. Such a methodology does not allow us to apply it directly to this research. However, the basic idea deserves to be reviewed. The forecasting of $\triangle E X U S_{t}$ is performed by ex-post simulation, and the RMSE and RMSPE are reported in Table 5. In addition to this the results are depicted in Figure 7. The periods are basically divided by a quarter and make an incremental period gradually. The last three cases are intensified for the periods which are psychological impact is mostly prevailed through the whole period. The result indicates that the model is comparatively unstable, since in most cases, the RMSE and RMSPE recorded more than 5\%. It implies that the psychological impact is an unstable influence in nature.

\section{Conclusion and Its Policy Implication}

The role of psychological information in determining the exchange rate was examined by investigating the Korean economic crisis which occurred between January 1997 to June 1999. In generating psychological information, news about economic fundamentals was the major source. The basic theory was that psychological information participates in forming the rational expectation, and accordingly it clears foreign exchange markets. That is, psychological information plays a key factor in exchange market clearing. It was found that the U.S. Dollar can be cleared by psychological impact. However, the outcomes weakly support the psychological hypothesis in exchange rate determination. The reason is that the GARCH-M model does not have strong stability, and this is also proven by historical simulation processes. Moreover, the result was obtained by evaluating the period of the Korean economic crisis and it would be an exaggerated psychological impact on economic analysis. However, at least, the result shows that the psychological factor is partly affected in exchange rate determination. In 
Table 5. Estimation of Simulation Errors

\begin{tabular}{|c|c|c|c|c|c|c|c|}
\hline Periods & $\begin{array}{l}\text { No. of } \\
\text { Group } i\end{array}$ & MSPE & RMSPE & Periods & $\begin{array}{l}\text { No. of } \\
\text { Group } i\end{array}$ & MSPE & RMSPE \\
\hline \multirow{3}{*}{$97.7-98.3$} & 5 & 0.7754 & 0.8424 & \multirow{3}{*}{$97.7-99.6$} & 5 & 0.8222 & 0.6065 \\
\hline & 7 & 0.7729 & 0.8265 & & 7 & 0.8220 & 0.5819 \\
\hline & 9 & 0.7770 & 0.7880 & & 9 & 0.8232 & 0.5658 \\
\hline \multirow{3}{*}{$97.7-98.6$} & 5 & 0.7947 & 0.7098 & \multirow{3}{*}{$98.1-98.6$} & 5 & 0.8282 & 0.4156 \\
\hline & 7 & 0.7936 & 0.6870 & & 7 & 0.8281 & 0.4207 \\
\hline & 9 & 0.7971 & 0.6485 & & 9 & 0.8277 & 0.4252 \\
\hline \multirow{3}{*}{$97.7-98.9$} & 5 & 0.7974 & 0.6543 & \multirow{3}{*}{ 98.4-98.12 } & 5 & 0.8168 & 0.4198 \\
\hline & 7 & 0.7974 & 0.6277 & & 7 & 0.8246 & 0.4143 \\
\hline & 9 & 0.8001 & 0.6075 & & 9 & 0.8364 & 0.4198 \\
\hline \multirow{3}{*}{$97.7-98.12$} & 5 & 0.7932 & 0.6103 & \multirow{3}{*}{$98.7-99.6$} & 5 & 0.8461 & 0.6355 \\
\hline & 7 & 0.7935 & 0.5864 & & 7 & 0.8444 & 0.5728 \\
\hline & 9 & 0.7966 & 0.5699 & & 9 & 0.8444 & 0.5606 \\
\hline \multirow{3}{*}{$97.7-99.3$} & 5 & 0.8217 & 0.6566 & & & & \\
\hline & 7 & 0.8211 & 0.6283 & & & & \\
\hline & 9 & 0.8225 & 0.6100 & & & & \\
\hline
\end{tabular}

Figure 7. Simulated Trends by Period.
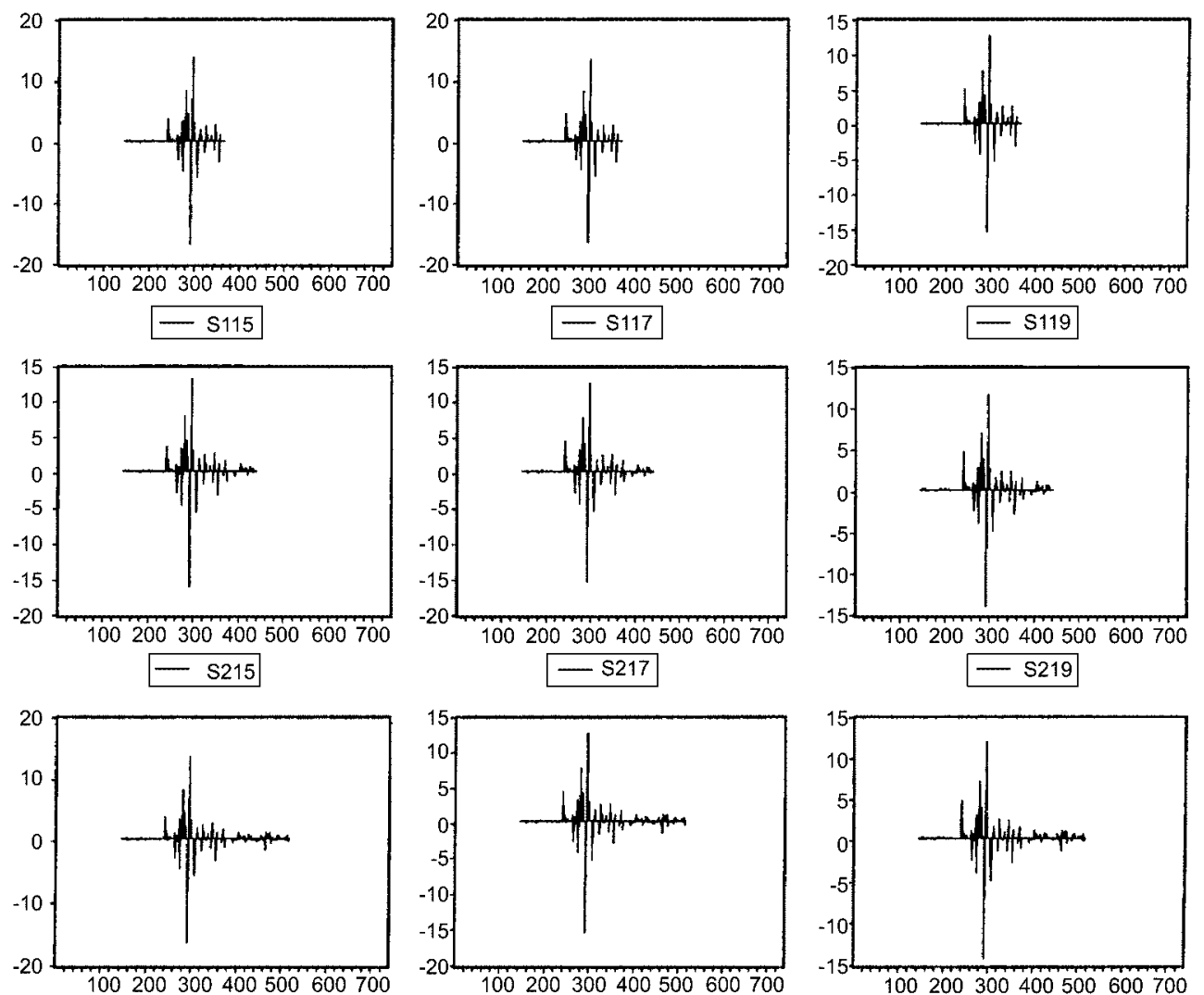
Figure 7. Continued
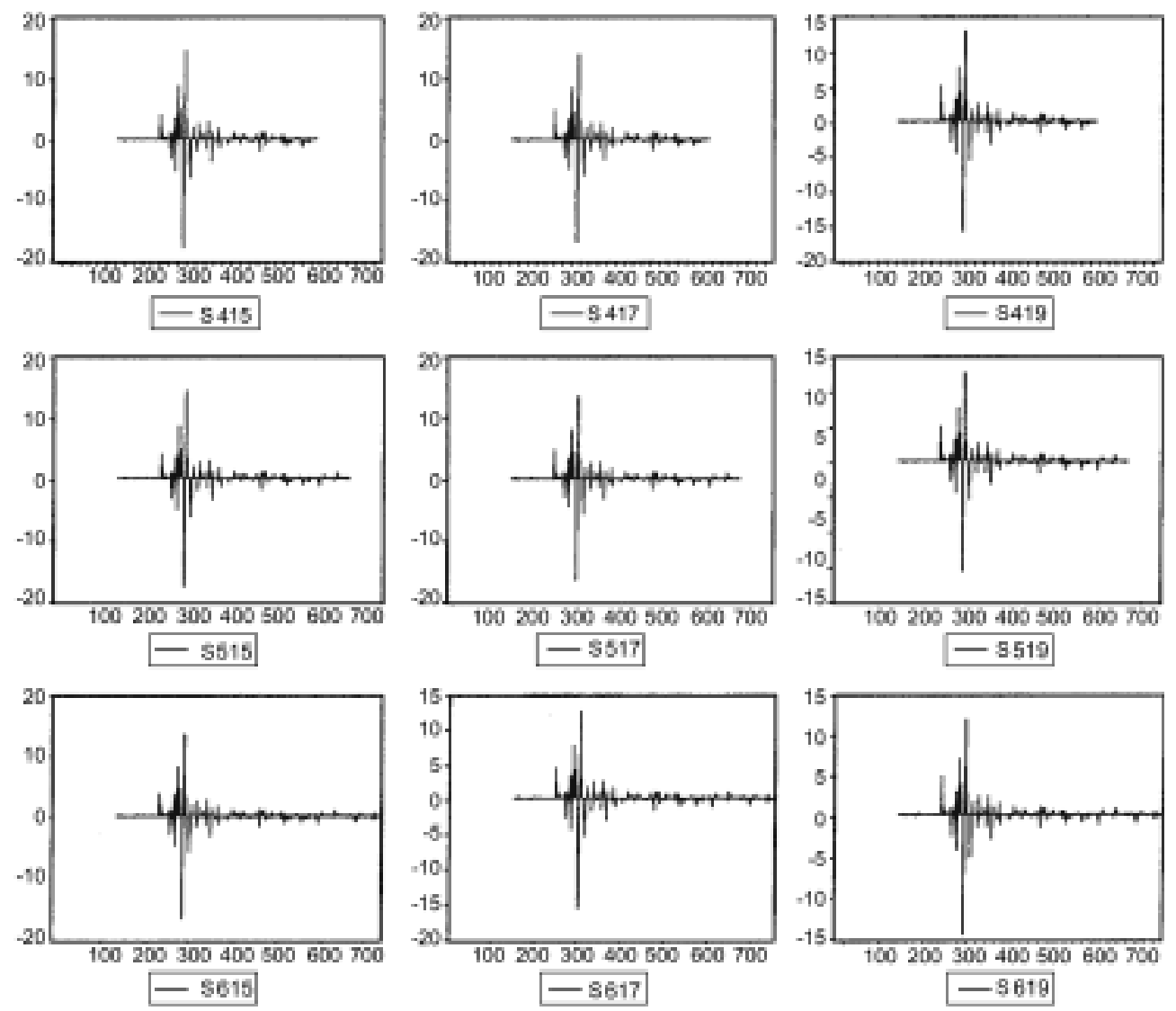

the very short run, it affects more than economic fundamentals.

Another implication is that the changing of the U.S. Dollar is an isolated factor in forming the psychological information in the foreign exchange markets. However, it may have the causation with psychological information. Also, it is ambiguous how the psychological impact affects demand or supply side. At least, the research shows that the understanding of psychological impact is necessarily for the implementation of economic policies, especially foreign exchange policies. A well designed model for analyzing psychological impact is to completely endogenized human behavior into the model. Further research in this field has to be ensue, and the research carefully analyze the psychological factor.

\section{Acknowledgement}

The research was performed while I was a Visiting Research Fellow at the Bank 
Figure 7. Continued
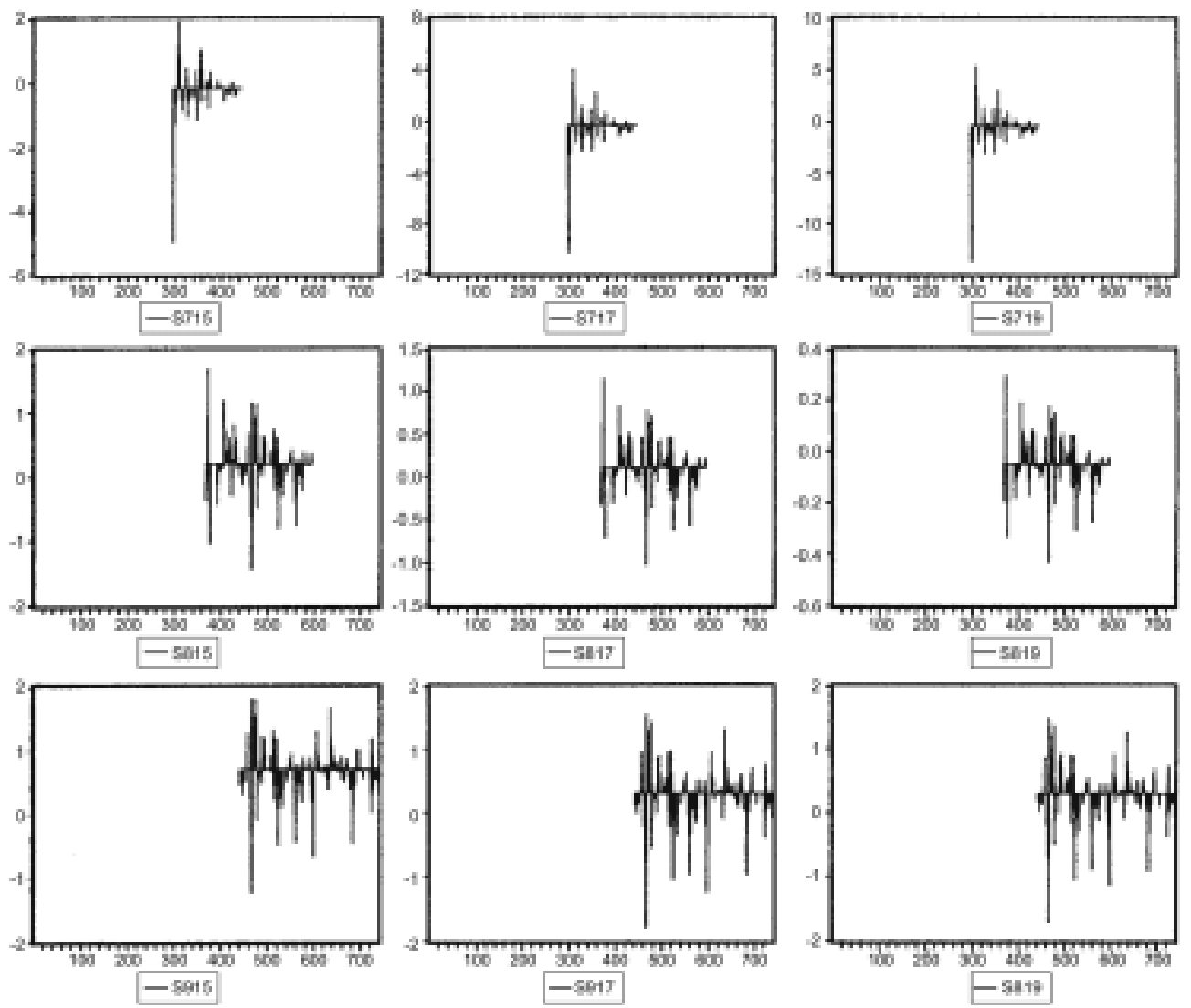

of Korea during the summer of 1999, and presented at the seminar which was held in the Bank of Korea on October, 1999. I would like to thank to the seminar participants for their helpful comments. And, the same goes to Seongtae Lee, Soon Sang Oh, and Young Seok Oh in the Bank of Korea for their research assistances. I am indebted to In-Yong Hong for compiling a part of data. However, all remaining errors are mine.

Date accepted: May 2000

\section{References}

Anderson, Michael, A. and Arthur, H. Goldsmith (1994) "Economic and Psychological

Theories of forecast Bias and Learning: Evidence from U.S. Business Manager's

Forecasts", Eastern Economic Journal, 20(4), 413-427.

Baudin, Louis (1957) “Albert Aftalion (1874-1956)”, Kyklos, 10(3). 
Berndt, E. K., B. H. Hall, R. E. Hall, and J. A. Hausman (1974) "Estimation and Inference in Nonlinear Structural Models," Annals of Economic and Social Measurement, 3(4), 653-665.

Bollerslev, T. (1986) "Generalized Autoregressive Conditional Heteroscedasticity", Journal of Econometrics, 31(3), 307-327.

Bollerslev, T., R. Y. Chou, and K. F. Kroner (1992) “ARCH Modeling in Finance: A Review of the Theory and Empirical Evidence", Journal of Econometrics, 52(1-2), 5-59.

Diba, Behzad, T. and Herschel I. Grossman (1988) "Explosive Rational Bubbles in Stock Prices?", American Economic Review, 78(3), 520-530.

Earl, Peter, E. (1990) "Economics and Psychology: A Survey", Economic Journal, 100(402), 718-755.

Engle, R. F. (1982) "Autoregressive Conditional Heteroscedasticity with Estimates of the Variance of United Kingdom Inflation”, Econometrica, 50(4), 987-1007.

Engle, R. F., Lilien, D. M., and Robins, R. P. (1987) "Estimating Time Varying Risk Premiums in the Term Structure: The ARCH-M Model", Economatrica, 55(2), 391-407.

Fishbein, M. A. and I. Ajzen (1975) Belief, Attitude, Intention and Behavior, Addison \& Wesley.

Frey, B. S. and R. Eichenberger (1991) “Anomalies in Political Economy”, Public Choice, 68(1-3), 71-89.

Hogarth, Robin, M. and Melvin W. Reder (1986) "Editor's Comments: Perspectives from Economics and Psychology", Journal of Business, 59(4), s185-s207.

Hopper, Gregory, P. (1997) "What Determines the Exchange Rate: Economic Factors or Market Sentiment?", Business Review, 17-29.

Lewin, Shira, B. (1996) "Economics and Psychology: Lessons for Our Own Day from the Early Twentieth Century", Journal of Economic Literature, 34(3), 1293-1323.

Maddala, G. S. (1992) Introduction to Econometrics, 2nd. ed., Macmillan Publishing Co.

Miller, G. A. (1956) The Magic Number Seven Plus or Minus Two: Some Limits on Our Capacity for Processing Information, Psychological Review, 67; 81-97.

Nelson, D. B. and C. Q. Cao (1992) "Inequality Constraints in the Univariate GARCH Model”, Journal of Business and Economic Statistics, 10(2), 229-235.

Ohanian, Lee E. (1996) "When the Bubble Bursts: Psychology or Fundamentals?", Business Review, FRB of Philadelphia, 3-13.

Rabin, Matthew (1998) "Psychology and Economics", Journal of Economic Literature, 36(1), 11-46.

Rhee, Hyun-Jae (1997) "An Empirical Study on the Exchange Rate Determination between U.S. Dollar and Korean Won: New Results from Johansen's Cointegration Methodology", Kukje Kyungje Yongu, 3(3), 129-151 (translated).

Shiller, R. J. (1989) Market Volatility, Cambridge, MIT Press.

Simon, Herbert, A. (1986) "Rationality in Psychology and Economics", Journal of Business, 59(4), s209-s224.

Smith, Vernon L. (1991) "Rational Choice: The Contrast between Economics and Psychology", Journal of Political Economy, 99(4), 877-897. 